\title{
AWARENESS AMONG MEDICAL STUDENTS REGARDING THE BINOCULARITY LEVEL IN THE COURSE OF FUTURE SPECIALTY CHOICE
}

\author{
Xeniya Fedoryak, Justyna Simiera, Piotr Loba \\ Medical University of Lodz, Łódź, Poland \\ Department of Binocular Vision Pathophysiology and Strabismus Treatment
}

\begin{abstract}
Background: Vision standards exist in many occupations with particular reference to medical science. The presence of a sufficient level of binocular vision is especially important in surgical specialty to perform visually demanding procedures. The purpose of this study was to reveal the level of awareness of one's binocular status among medical students, and the significance of having binocular vision in terms of specialty choice. Material and Methods: A self-constructed questionnaire was given to all subjects enrolled in the study. The first group comprised 53 students from the second and third year of the Medical University of Lodz, who then underwent an ophthalmological examination with binocularity assessment. The second group included 57 students of the last years of the Medical Faculty, who did the same survey and outlined how the ophthalmology course improved their knowledge of stereoacuity and vision requirements for the chosen specialty. Statistical analysis was performed using Person's $\chi^{2}$ test. Results: Overall, $32 \%(\mathrm{~N}=17)$ of the students from the first group and $84 \%(\mathrm{~N}=48)$ from the second group stated to be familiar with the term "binocularity" and its importance in performing surgical procedures. The awareness of the existing occupational contraindications related to low visual acuity and binocularity was declared by $16 \%(\mathrm{~N}=9)$ and $54 \%(\mathrm{~N}=31)$ of the subjects included in each group, respectively. University lectures were indicated as the main source of knowledge by $28 \%(\mathrm{~N}=15)$ of the individuals from the first group and by $59 \%(\mathrm{~N}=39)$ from the second group. The ophthalmology course was considered to be sufficiently covering the basics needed for the future doctor by 34 resident physicians (60\%). Conclusions: The medical students' awareness of their own binocular status appears low. There is a strong need for implementing at least some quality standards for visual assessment to decide if a given student has an adequate eye function to participate in surgical procedures. Med Pr. 2020;71(1):9-16
\end{abstract}

Key words: medical students, binocular vision, vision standards, stereoacuity, medical specialty, occupational requirements

Corresponding author: Xeniya Fedoryak, Medical University of Lodz, Department of Binocular Vision Pathophysiology and Strabismus Treatment, Stefana Kopcińskiego 22, 90-153 Łódź, Poland, e-mail: xeniyalissa@gmail.com

Received: March 19, 2019, accepted: October 8, 2019

\section{INTRODUCTION}

Visual standards exist as demands for everyone in the majority of occupations in order to protect the individuals and others in their work, and to ensure that one can perform all the tasks needed for the job under any circumstances.

With particular reference to medical science, a surgeon is nowadays often required to perform visually demanding tasks, including microsurgery and advanced endoscopic procedures. Although modern surgical simulators offer the opportunity to reveal the visual requirements for performing specific tasks in a safe environment, showing advantages of stereopsis in the surgical procedures that require precise hand-eye coor- dination, the practical impact of stereoacuity has largely been undervalued [1].

Previous studies have provided evidence of a higher efficiency of reach performance during binocular viewing [2] and of the importance of stereopsis for medical practitioners [3] whose job is related to small object manipulation. Additionally, among resident physicians who were asked to perform eye-hand coordination related tasks, those with the lack of binocularity achieved worse results.

According to the search performed by the authors of this paper, only in the United Kingdom the Royal College of Ophthalmology has a published recommendation "to seek an assessment for stereovision measuring" [4], and this recommendation is specific to the

Funding: this research was supported by the Medical University of Lodz (grant No. 502-03/1-007-02/502-14-244 entitled "Wykorzystanie obiektywnych badań ortoptycznych w diagnostyce i leczeniu zezów towarzyszących i nietowarzyszacych" [Applicability of objective orthoptic tests in diagnosing comitant and incomitant strabismus], grant manager: Justyna Simiera). 
ophthalmic specialists training. To the best of the authors' knowledge, so far neither Poland nor any other European country has developed a documented standard requirement for binocularity assessment before starting surgical specialty.

The above data provoked the authors to consider whether the level of knowledge provided by the university was sufficient for the students to fully understand the importance of binocular vision and depth perception in their future medical practice, especially in performing surgical procedures.

The main purpose of this study was to reveal the level of awareness of the term "binocularity" among medical students, one's binocular status and the importance of having binocular vision in terms of specialty choice. The second objective was to review the source of this awareness - university/books/one's own interest, and to check whether the level of knowledge given by the University was enough for the students to fully understand the ophthalmological contraindication for the chosen specialty.

\section{MATERIAL AND METHODS}

The study was divided into two parts: the first part included questionnaires and ophthalmological checkups; the second part required filling out the questionnaire only. The characteristics of the participants' groups are described in Table 1.

As a first step, students of the second year of the $6 \mathrm{MD}$ program at the English Division of the Medical University of Lodz, as well as students of the third year of the Medical Faculty at the Polish division were asked to participate in the practical part of the research.

An anonymous, self-constructed 16-point questionnaire (Appendix 1) was given to the students who were willing to take part in the research. The authors recorded the following data for all the participants: sex, age, year and field of studies and future specialty (if chosen). Additionally, the survey included questions concerning the frequency of ophthalmologist visits, the presence of eye diseases, the use of refractive correction or past eye surgeries; as well as questions essential for the studied subject - awareness of the terms "binocular vision and/ or stereopsis," the source of knowledge (self-interest/ university lectures/extracurricular studies/other) and the appreciation of ophthalmological contraindications existing for the chosen specialty.

To verify the actual knowledge of the subject among the students, every student giving a positive answer concerning the familiarity with the term "stereoscopic/ binocular vision" was asked to briefly describe orally its meaning to the examiner; thus, if the response was not consistent with the definition (or with the common understanding of the term, taking into account the importance of binocular vision in performing surgical procedures), the answer in the questionnaire was changed by the examiner.

Subsequently, all the enrolled subjects from the first study group underwent an ophthalmological examination including autorefractometry, the measurement of visual acuity using Snellen charts. Bagolini striated glasses were used to establish the presence or absence of binocular functions, and with a view to conducting the

Table 1. A division into participants' groups in the research about awareness among medical students regarding the binocularity level in the course of future specialty choice carried out in Medical University of Lodz on January-March 2018

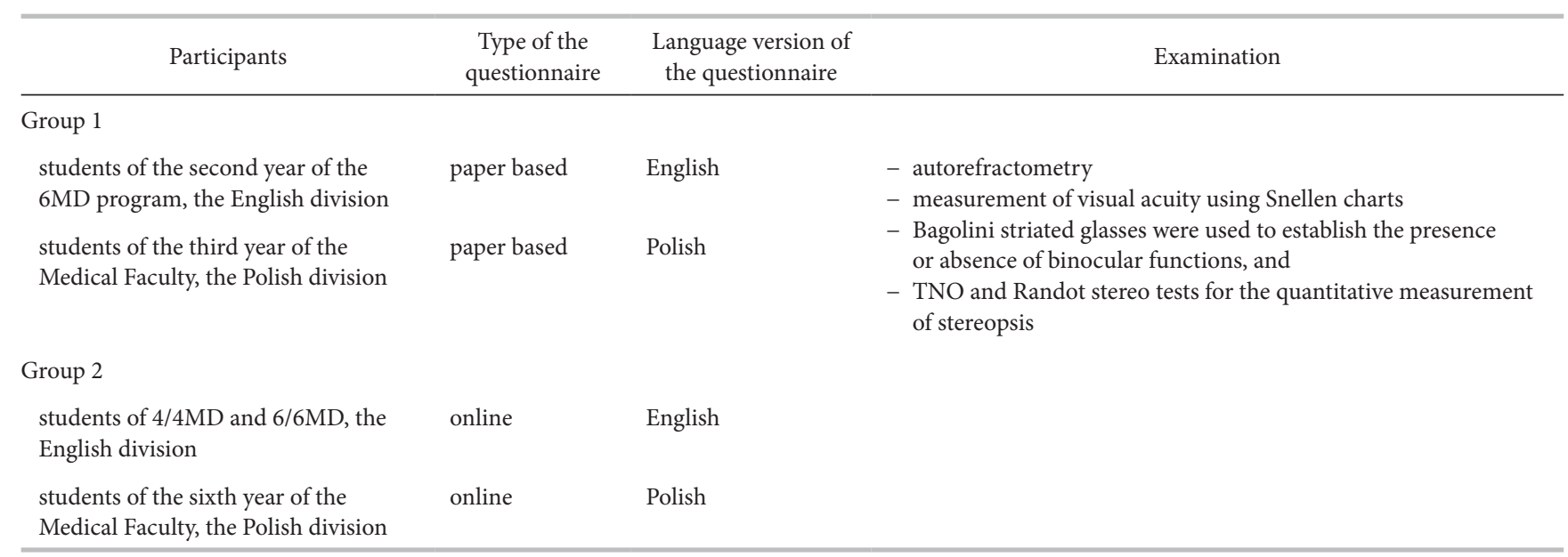


quantitative measurement of stereopsis, TNO and Randot stereo tests (measured in seconds of arc) were performed. To detect and measure potent ocular deviation, the alternate prismatic cover test was used.

Simultaneously, an online questionnaire in English and Polish was given to the students of both the Polish and English divisions, attending their last year of studies (Medical studies 6 year curriculum [6/6MD] and 4 years curriculum [4/4MD] for English, and the sixth year of the Medical Faculty for Polish). The survey consisted of the same repeated basic information part and key questions about the recognition of the terms "binocularity/stereopsis," the source of awareness and contraindications for the future specialty. The last part concerned the ophthalmology course of conducted at the Medical University of Lodz and, more specifically, whether it was considered sufficient for the future doctor and whether the essentials it covered included mentioning the importance of binocularity and stereoacuity in the course of performing fine motor tasks, especially in surgery.

\section{Ethics}

The study protocol was approved by the Institutional Review Board of the Medical University of Lodz (decision No. RNN/140/18/KE). Informed consent was obtained from each subject.

\section{Statistics}

Person's $\chi^{2}$ test was used to compare the difference between the presented levels of awareness in the studied groups. A p value of $\leq 0.05$ was considered statistically significant.

\section{RESULTS}

A total of 110 participants were enrolled in both stages of the study, including 53 subjects undergoing checkups (group 1) and 57 senior medical students filling out the required questionnaire (group 2). Figure 1 shows the sex and studies distributions among the groups.

In group 1, according to the questionnaire results, the last ophthalmological checkup was done in the previous $24 \pm 10$ months, and $7.5 \%$ of the students had never been checked by an ophthalmologist. In the presented group, the mean frequency of ophthalmologist visits was only once, reported by $86 \%$ of the participants, and it ranged from never or once (86\%), through every 1 to 3 years (11\%), to twice a year (3\%).

More than half of the participants were using glasses $(\mathrm{N}=31)$, in the majority of cases for less than a year $(\mathrm{N}=25)$, while only 1 individual underwent laser correction.

Among all the students participating in the research, $32 \%(\mathrm{~N}=17)$ declared the choice of the surgical spe-

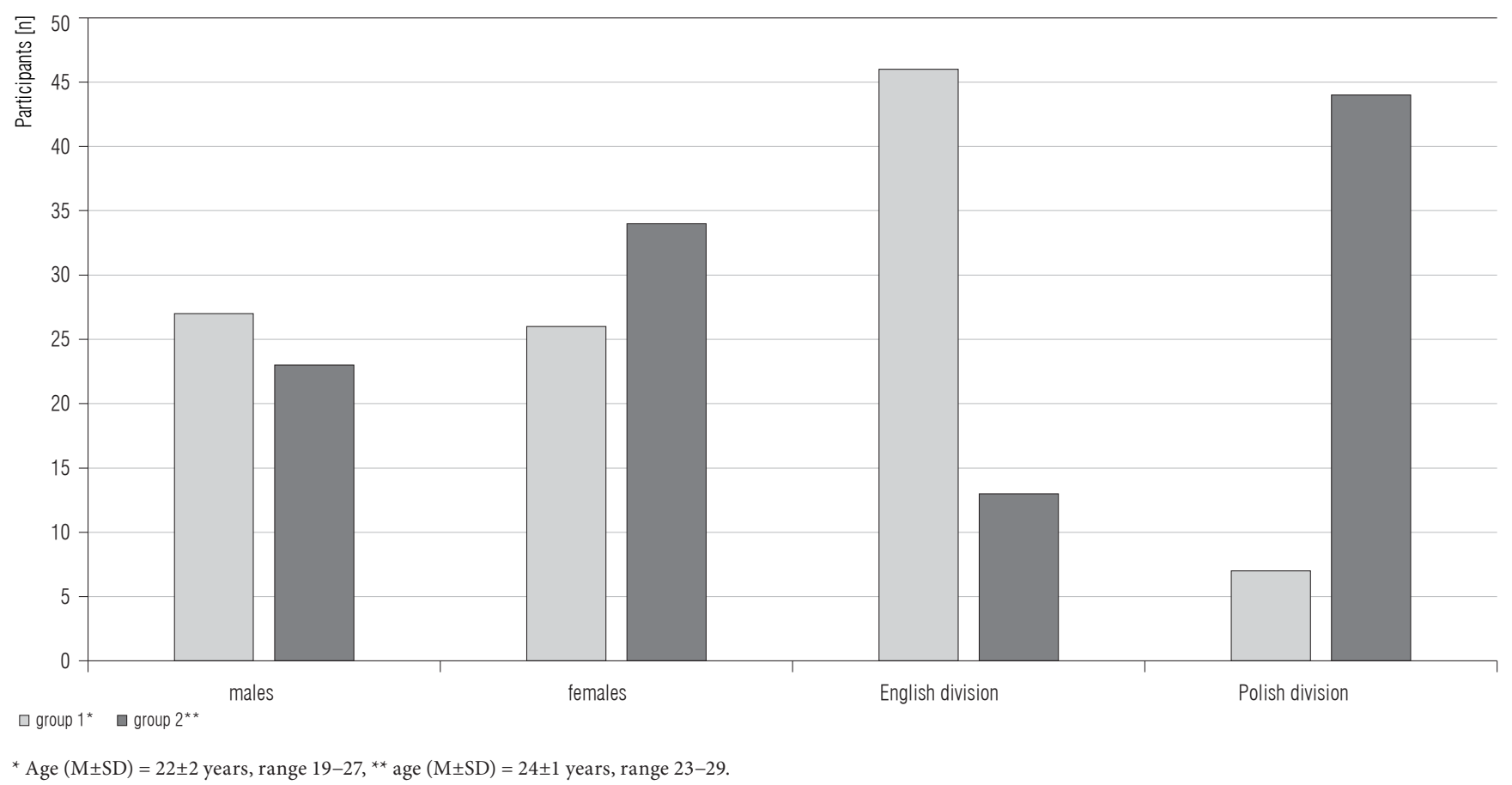

Figure 1. Distribution of sex, age and affiliation to the University division in the studied groups of medical students of Medical University of Lodz, January-March 2018 


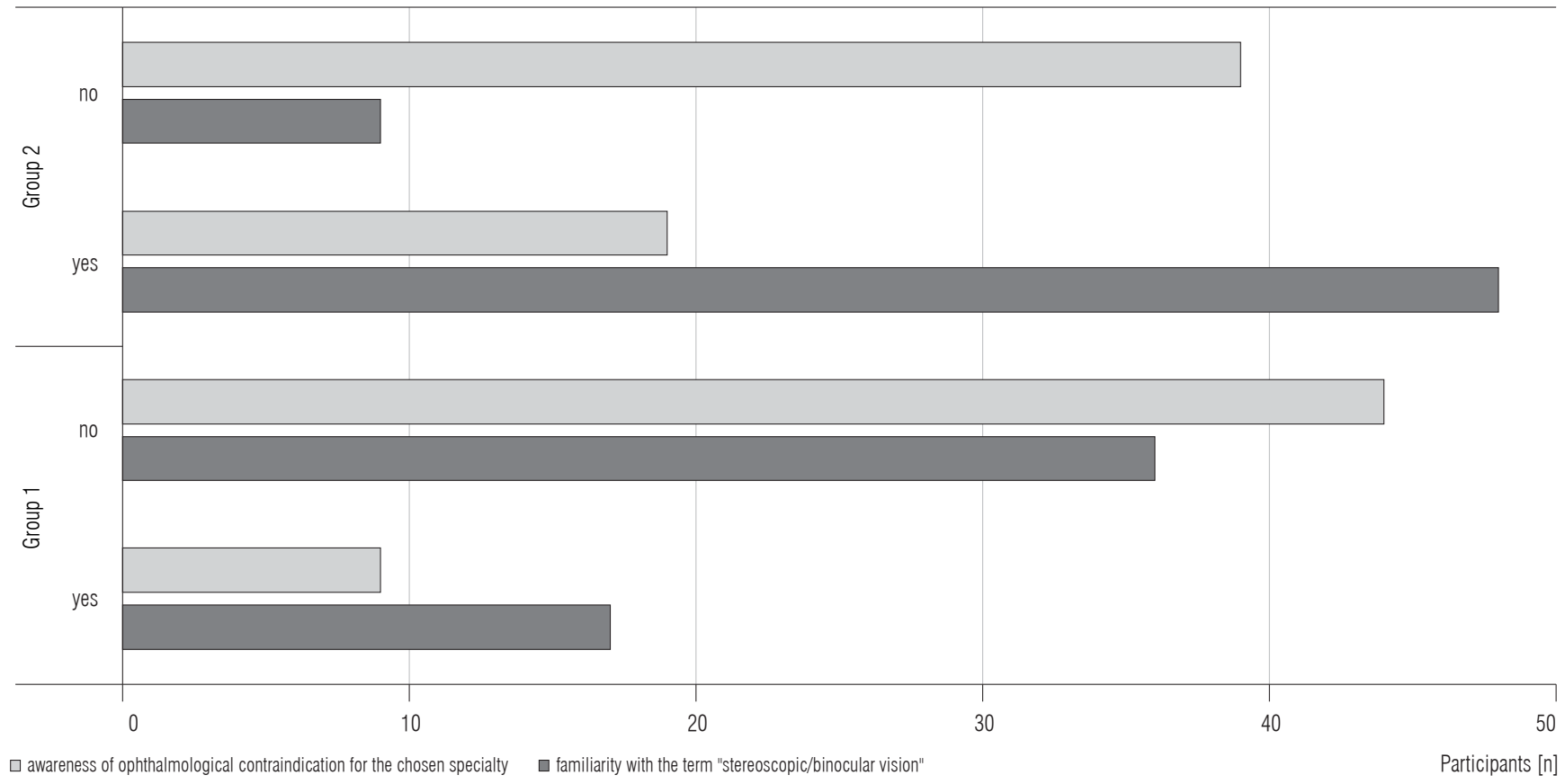

Figure 2. Awareness of ophthalmological contraindications existing for the chosen specialty and familiarity with the term "stereoscopic/binocular vision" among the participants in the studied groups of medical students of Medical University of Lodz, January-March 2018

cialty in the future. More than half $(64 \%, \mathrm{~N}=34)$ were aware of their own visual acuity, while only $52 \%$ were able to specify the ophthalmological problem they had.

Concerning the familiarity with the term "binocularity" and its importance in performing surgical procedures, Figure 2 shows the comparison of the results obtained from both studied groups. As the main source of knowledge, only $28 \%(\mathrm{~N}=15)$ of the subjects from Group 1 stated university lectures.

In the same group, $62 \%$ were orthophoric and $24 \%$ had a stereopsis level out of the normal range (>100 s of arc). The average amount of stereopsis on the Randot and TNO tests was $62.6 \pm 47.7 \mathrm{~s}$ of arc and $108 \pm 118 \mathrm{~s}$ of arc, respectively. Only 1 participant had a negative result in the Bagolini test.

Out of 57 subjects included in group 2 (Figure 1), $32 \%$ reported that they had not chosen their specialty yet, while among the rest of the studied group, $9 \%$ were inclined to perform surgical procedures. Among 48 participants familiar with the term "binocularity" (Figure 2), $72 \%(\mathrm{~N}=41)$ recalled being informed about it during the ophthalmology course provided by the Medical University of Lodz. Surprisingly, only 59\% ( $\mathrm{N}=39)$ of the individuals indicated the University as the source of knowledge for both "binocularity" and ophthalmological contraindications for the chosen specialty.
Considering the last issue under consideration, the obtained data showed that, while 31 students (54\%) stated to be informed about the possible ophthalmic obstacles for their future specialty during the attended classes, $66 \%(\mathrm{~N}=38)$ were unaware of the possible contraindications they might encounter (Figure 2). In general, 34 senior resident physicians $(60 \%)$ considered the ophthalmology course provided by the University to be sufficiently covering the basics of knowledge needed for the future doctor.

The observed difference between the studied groups regarding the familiarity with the terms "stereoscopic/ binocular vision" was statistically relevant $\left(\chi^{2}=30.88\right.$, $\mathrm{p}<0.05$ ). A statistically significant difference was also found between the groups concerning the awareness of the existing contraindications for the chosen specialty $\left(\chi^{2}=3.87, \mathrm{p}<0.05\right)$.

\section{DISCUSSION}

According to the recent recommendations regarding adults, the suggested frequency of ophthalmological checkups ranges from at least every 4 years to annually, depending on the risk group affiliation [5]. The present study suggests that the low frequency of ophthalmologist visits among medical students of younger years is 
strictly connected to their low consciousness of the visual status and the need for refractive error correction.

The observed frequency of these visits in the study group is normal for the students of their age, but the fact that stereopsis tests are not included in the routine procedures of the basic ophthalmological examination leads to a continuously low level of awareness of its importance. Consequently, the low level of awareness raises the question whether the stereopsis test itself is sufficient to predict the success of the potential surgeon.

The conduction of the ophthalmology course at a later stage of university education is likely to have contributed to the low familiarity with the term "stereoscopic/ binocular vision" in the studied group, followed by the low awareness of the potential visual contraindications in the chosen specialty, implicating the fact that first, and generally uninformed, choices are made exactly on the first years of studies.

Furthermore, contrary to the authors' expectations, the results achieved by the representatives of group 2 were surprising - three-quarters of the students were informed about the term in question during the ophthalmology course provided by the University. More than half of the respondents stated that the course sufficiently covered the basic knowledge needed to make an informed decision about the future specialty. Contrary to that, this study has shown the persistently low awareness of the known contraindications among the students, even in the most often chosen fields of future work. It is, therefore, too early to conclude about the efficacy of the course. Those results may, however, be biased by the fact that the Ophthalmology Department at the Medical University of Lodz has a separate strabismus subdepartament which is not a standard for other universities in Poland. In addition, while binocularity is a topic that is routinely discussed during ophthalmology classes in every medical curriculum, the question of the need for an early explanation of the binocularity importance during pre-clinical years remains open.

Binocular vision makes it possible to detect differences between the 2 eyes' views [6], meaning that it is crucial for performing vision-related tasks, such as the quality of life [7], object prehension [8], object placement [9], or rapid distance estimation [10,11], and for other tasks involving fine motor skills [12].

Around 5\% of the general population are reported to suffer from stereoblindness (a total lack of stereoscopic vision) $[13,14]$ and an even higher percentage have stereo-impairment (a difficulty using stereoscop- ic cues for depth perception [6]), potentially estimated at $30 \%$ [15].

So far, there has been no definite evidence that stereopsis directly influences the visual-spatial performance [16] in surgical practice [17], while the role of manual dexterity has been confirmed in previous studies [16].

Moreover, it is worth noting that individuals with no stereopsis [16] and low visual-spatial test scores face more difficulties while performing spatially complex procedures $[18,19]$ but the results improve with learning and practice time [20].

To the best of the authors' knowledge, this is the first study to investigate medical students' awareness of binocularity and its importance in clinical practice.

Wong [1] found the existence of visual standards in only 2, out of 22, studied countries and, together with the study conducted by Nibourg [21], strongly suggested the introduction of vision requirements for surgeons, especially those for performing microsurgeries.

Due to the lack of existing standards for testing stereopsis in potential surgical trainees [22], at least some quality standards for visual assessment should be implemented to facilitate a decision if a given student has an adequate eye function to participate in surgical procedures [23].

In the authors' opinion, it is worth reconsidering the ophthalmology course provided by the Medical University of Lodz on the fifth year of studies, by adding some specific information clarifying the role of binocularity in fine motor tasks, especially in surgical procedures. That would help the students to fully weigh the pros and cons when choosing their specialty, in view not only of their own interests and skills, but also of the visual requirements and anatomical specificities of each individual.

With consideration of the previously mentioned data, a question can be raised concerning the efficacy of the present-day approach which allows students to determine their preferred specialty. There is a need for introducing additional, more functional tests to evaluate the students' predisposition to be a surgeon.

\section{CONCLUSIONS}

The awareness of binocular vision and its importance in terms of specialty choice is low among the younger years students but it seems to improve after taking the ophthalmology course. The University is stated to be the source of knowledge but the course provided is 
worth reconsidering by focusing more on the existing ophthalmological limitations in different specialties.

\section{ACKNOWLEDGMENTS}

The authors would like to thank Olga Fahim and Margaryta Guliaieva for their support in the preparation of the manuscript.

\section{REFERENCES}

1. Wong NW, Stokes J, Foss AJ, McGraw PV. Should there be a visual standard for ophthalmologists and other surgeons? Postgrad Med J. 2010;86(1016):354-8, https://doi.org/doi: 10.1136/pgmj.2009.091371.

2. Gnanaseelan R, Gonzalez DA, Niechwiej-Szwedo E. Binocular advantage for prehension movements performed in visually enriched environments requiring visual search. Front Hum Neurosci. 2014;8:959, https://doi.org/doi:10.3389/fnhum.2014.00959.

3. Al-Saud LM, Mushtaq F, Mirghani I, Balkhoyor A, Keeling $\mathrm{A}$, Manogue $\mathrm{M}$, et al. Drilling into the functional significance of stereopsis: the impact of stereoscopic information on surgical performance. Ophthalmic Physiol Opt. 2017;37(4):498-506, https://doi.org/doi:10.1111/opo.12393.

4. The Royal College of Ophthalmologists [Internet]. The Collage; 2018 [cited 2018 Mar 19]. Ophthalmic Specialist Training Essential Attributes. Available from: https://www. rcophth.ac.uk/curriculum/ost/entering-ost/.

5. American Academy of Ophthalmology. Frequency of Ocular Examinations [Internet]. The Academy; 2015 [cited 2015 Mar 3]. Available from: https://www.aao.org/clinical-statement/frequency-of-ocular-examinations.

6. Macknik SL, Martinez-Conde S. Dichoptic visual masking reveals that early binocular neurons exhibit weak interocular suppression: implications for binocular vision and visual awareness. J Cogn Neurosci. 2004;16(6):1049-59, https:// doi.org/10.1162/0898929041502788.

7. Rahi JS, Cumberland PM, Peckham CS. Visual impairment and vision-related quality of life in working-age adults: findings in the 1958 British birth cohort. Ophthalmology. 2009;116:270-4, https://doi.org/10.1016/j.ophtha. 2008.09.018.

8. Bradshaw M, Elliott KM, Watt SJ, Hibbard PB, Davies IR, Simpson PJ. Binocular cues and the control of prehension. Spat Vis. 2004;17:95-110, https://doi.org/10.1163/15685680 4322778288.

9. Levi DM, Knill DC, Bavelier D. Stereopsis and amblyopia: A mini-review. Vision Res. 2015;114:17-30, https://doi.org/ 10.1016/j.visres.2015.01.002.
10. Caziot B, Valsecchi M, Gegenfurtner KR, Backus BT. Fast perception of binocular disparity. J Exp Psychol Hum Percept Perform. 2015;41:909-16, https://doi.org/10.1037/xhp 0000066.

11. McKee SP, Taylor DG. The precision of binocular and monocular depth judgments in natural settings. J. Vis. 2010;10:5, https://doi.org/10.1167/10.10.5.

12. Sheedy JE, Bailey IL, Buri M, Bass E. Binocular vs. monocular task performance. Am. J. Optom. Physiol. Opt. 1986; 63:839-46, https://doi.org/10.1097/00006324-19861000000008.

13. Bosten JM, Goodbourn PT, Lawrance-Owen AJ, Bargary G, Hogg RE, Mollon JD. A population study of binocular function. Vision Res. 2015;110:34-50, https://doi.org/10.1016/ j.visres.2015.02.017.

14. Tam WJ, Stelmach LB. Display duration and stereoscopic depth discrimination. Can J Exp Psychol. 1998;52:56-61, https://doi.org/10.1037/h0087280.

15. Hess RF, To L, Zhou J, Wang G, Cooperstock JR. Stereo Vision: The Haves and Have-Nots. Iperception. 2015; 6:2041669515593028, https://doi.org/10.1177/2041669515 593028 .

16. Murdoch JR, McGhee CN, Glover V. The relationship between stereopsis and fine manual dexterity: pilot study of a new instrument. Eye (Lond). 1991;5(Pt 5):642-3, https:// doi.org/doi:10.1038/eye.1991.112.

17. Wanzel KR, Hamstra SJ, Caminiti MF, Anastakis DJ, Grober ED, Reznick RK. Visual-spatial ability correlates with efficiency of hand motion and successful surgical performance. Surgery. 2003;134(5):750-7, https://doi.org/10.10 16/s0039-6060(03)00248-4.

18. Rossi JV, Verma D, Fujii GY, Lakhanpal RR, Wu SL, Humayun MS, et al. Virtual vitreoretinal surgical simulator as a training tool. Retina. 2004;24(2):231-6.

19. Hamstra SJ, Dubrowski A. Effective training and assessment of surgical skills, and the correlates of performance. Surg Innov. 2005;12(1):717, https://doi.org/doi:10.1177/ 155335060501200110 .

20. Krupinski EA, Graham AR, Weinstein RS. Characterizing the development of visual search expertise in pathology residents viewing whole slide images. Hum Pathol. 2013;44(3):357-64, https://doi.org/doi:10.1016/j.humpath. 2012.05.024.

21. Nibourg LM, Wanders W, Cornelissen FW, Koopmans SA. Influence of stereoscopic vision on task performance with an operating microscope. J Cataract Refract Surg. 2015; 41(9):1919-25, https://doi.org/doi:10.1016/j.jcrs.2014.12.066.

22. Elliott A. Is stereopsis essential to be a competent ophthalmic surgeon? A literature review [Internet]. Semantic Scholar; 2008 [cited 2018 Mar 19]. Available from: https:// 
www.semanticscholar.org/paper/Is-stereopsis-essential-tobe-a-competent-surgeon-\%3F-Elliott/fe86bc063b66elfb2ea129637987f511bdae9b66.
23. Lança C, Thompson JD, Lança L, Hogg P. Visual Function Assessment in Medical Imaging Research. Radiol Technol. 2015;87(2):129-38 
Appendix 1. The English version of the questionnaire

\begin{tabular}{|c|c|c|}
\hline \multicolumn{3}{|l|}{ 1. Participants number } \\
\hline 2. Sex & male & female \\
\hline \multicolumn{3}{|l|}{ 3. Age } \\
\hline \multicolumn{3}{|l|}{ 4. Year of studies, field of studies } \\
\hline \multicolumn{3}{|l|}{ 5. Future specialty (if chosen) } \\
\hline \multicolumn{3}{|c|}{ 6. When was your last ophthalmologic checkup? How often do you see your ophthalmologist? } \\
\hline \multicolumn{3}{|l|}{ 7. Are you aware of your visual acuity? } \\
\hline \multicolumn{3}{|l|}{ 8. Are you diagnosed with any eye disease? If YES, please specify. } \\
\hline \multicolumn{3}{|l|}{ 9. Are you aware of any eye problems you have? } \\
\hline 10. Have you ever been prescribed glasses/lenses? & yes & no \\
\hline \multicolumn{3}{|l|}{ 11. If YES, how long have you been using these corrections? } \\
\hline \multicolumn{3}{|l|}{ 12. If question 7 answer is YES, what is the strength of the lenses you use? } \\
\hline 13. Have you ever undergone laser vision correction? & yes & no \\
\hline 14. Are you familiar with the term "stereoscopic/binocular vision"? & yes & no \\
\hline 15. If YES, please indicate the source of knowledge & $\begin{array}{l}\text { a) self interest } \\
\text { b) university lectures } \\
\text { c) extracurricular studies } \\
\text { d) others }\end{array}$ & \\
\hline
\end{tabular}

I hereby give my permission to collect and store my personal information for research and statistical purposes. I have been explained and understood upcoming procedures and conditions of participation. (I understand what is being asked of me. My questions have been answered.) I freely agree to participate and have not been coerced into participation. I understand that participation is voluntary and that I may withdraw at any time without penalty.

This work is available in Open Access model and licensed under a Creative Commons Attribution-NonCommercial 3.0 Poland License - http://creativecommons.org/licenses/by-nc/3.0/pl/deed.en. 